\title{
Arc Root Commutation From Moving Contacts in Low Voltage Devices
}

\author{
John W. McBride, Kesorn Pechrach, Member, IEEE, and Paul M. Weaver
}

\begin{abstract}
This paper focus on the arc commutation from a moving contact and in particular on the anode motion of a high current arc in low voltage current limiting circuit breakers. Recent investigations have observed that the anode arc root motion is affected by arc chamber geometry. It was previously assumed that cathode root motion was the dominant process. The study uses a flexible test apparatus with a solid state high speed imaging system. The experimental results presented show the influence of arc chamber venting, current level, current polarity and contact velocity on arc motion. Particular emphasis is made to the anode motion. The physical process occurring in the anode root are discussed and related to the observed motion. The results show that the anode root is retarded at the tip of the moving contact and that this is primarily related to the venting process in the arc chamber.
\end{abstract}

Index Terms-Arc chamber, circuit breakers, contact velocity, high current arc.

\section{INTRODUCTION}

$\mathbf{T}$ HE COMMUTATION of an arc root from a moving contact is essential to the performance of a wide range of switching devices. This paper focuses on the events affecting the arc commutation and in particular on the anode root motion. The study of anode motion in high current switching devices has often been neglected at the expense of the apparently more dominant phenomena at the cathode arc root. Recent studies have shown that although the cathode root is important there are cases where the motion of the anode root can dominate arc motion and therefore the performance of low voltage switching devices [1], [19]. The main emphasis of the work presented here is applied to low voltage current limiting devices. This paper presents experimental results from a test system designed to recreate the current limiting operation of a miniature circuit breaker (MCB). Miniature circuit breakers are widely used in domestic, commercial and light industrial installations. The devices are usually used where the supply voltage exceeds $200 \mathrm{~V}$ ac and are used to protect circuits rated up to $100 \mathrm{~A}$ from overload and short circuit faults $\left(10^{3}-10^{4} \mathrm{~A}\right.$ prospective). During a short circuit fault an electric arc is drawn between opening contacts. The current through the conductors of the MCB generates a magnetic field in the arc chamber, which acts to force the arc away from the con-

Manuscript received September 28, 2000; revised April 1, 2001. This work was supported by EPSRC and Chugai (USA). This work was recommended for publication by Associate Editor M. Braunovic upon evaluation of the reviewers' comments.

J. W. McBride and K. Pechrach are with the School of Engineering Science, Electro-Mechanical Research Group, University of Southampton, Southampton S017 1BJ, U.K.

P. M. Weaver is with PBT, Ltd., Harlow CM20 2BN, U.K.

Publisher Item Identifier S 1521-3331(01)04149-6.

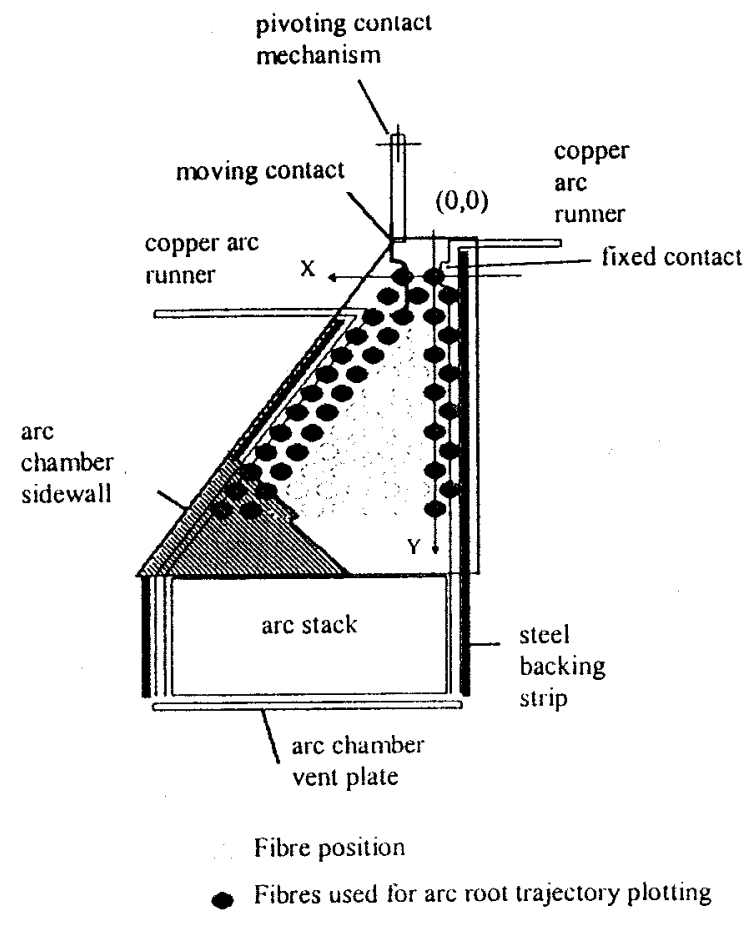

Fig. 1. Arc chamber geometry used with the fixed contact connected to a long straight runner. The circles identify optical fiber positions; the dark circles are positions used to monitor arc root motion.

tact region along arc runners and into an arc stack, see Fig. 1. The arc is then split into a number of series arcs, which results in a high voltage across the circuit breaker. The high voltage counteracts the supply voltage and limits the peak fault current. The energy released by the fault is reduced and damage to both the circuit and the circuit breaker is minimized. This paper follows on from previously published papers [1]-[3], [19] where the test system and arc imaging system used here were described in detail. Fig. 1 shows details of the arc chamber used in these studies. The arc is drawn between the opening contacts at the top of the figure and forced downwards into the arc stack.

\section{REVIEW OF ARC Motion Studies}

As techniques to record arc behavior have improved more details of arc phenomena have emerged. Arc immobility at the ignition site, arc commutation, periods of reduced arc motion, and the arc running time (arc lengthening time) have all been identified as separate phenomena [2], [4], [5]. In many cases investigations have been conducted on parallel arc runners, without 
TABLE I

CONSTANTS Used IN THE EXPERIMENTAL PROCEDURE

\begin{tabular}{l||l}
\hline \hline Factor & Constant Value \\
\hline $\begin{array}{l}\text { Capacitor charge } \\
\text { voltage }\end{array}$ & $\begin{array}{l}\text { Variable to obtain } \\
\text { current levels. }\end{array}$ \\
\hline Inductance & $224 \mu \mathrm{H}$ \\
\hline Capacitance & $47.4 \mathrm{mF}$ \\
\hline Final contact gap & $6 \mathrm{~mm}$ \\
\hline $\begin{array}{l}\text { Contact mechanism and } \\
\text { velocity }\end{array}$ & $\begin{array}{l}\text { Pivoting mechanism } \\
10 \mathrm{~m} / \mathrm{s}, 4 \mathrm{~m} / \mathrm{sec},\end{array}$ \\
\hline Moving contact & $5.5 \mathrm{~m} / \mathrm{sec}$. \\
\hline Contact polarity & Silver plated copper \\
\hline Contact opening delay & Variable \\
\hline$t_{\text {cod }}$ & $500 \mu \mathrm{s}$ \\
\hline Chamber depth & $6 \mathrm{~mm}$ \\
\hline Chamber attitude & Horizontal \\
\hline Arc stack displacement & $35 \mathrm{~mm}$ \\
\hline \hline
\end{tabular}

opening contacts. The investigation presented here makes use of an optical fiber imaging system with image processing methods to identify the details of the events which affect the arc motion as the high current arc is ignited between opening contacts.

There are many examples where results on arc motion show a high degree of variability. This is often a result of the experimental system and measurement method used. The experimental system used here has been demonstrated to show good reliability in results and the arc chamber has been designed to minimize variables which are known to affect arc motion.

In a recent review [6], a comparison was drawn between the various methods used in the study of arc motion. There have been numerous studies of cathode root motion [7]-[10], since the cathode root as the electron source was thought to dominate arc motion, however recent results [1], [19] have demonstrated the importance of anode motion.

\section{A. Anode Motion}

In an experimental study [11] the arc was ignited between parallel runners and the motion of the arc studied with a single optical fiber and a streak camera. The delay of cathode and anode roots over various size steps and gaps in conductors were presented, however the commutation delay measured was not clearly defined. It was shown that the delay with a step geometry was greater for the cathode root. This was also the case for a gap geometry. The magnitude of the delays are not relevant here as they are not sufficiently well defined, however in the case of the gap the cathode delay was approximately 10 times longer, for gap widths 1-5 mm. It was identified that the anode spot jumps over the gap but does not move into the gap. In a further observation of importance it was noted that if the anode spot is delayed, then it seems more impeded than a cathode spot under similar situations. A stationary anode spot eroded the surface more severely than a cathode spot and the arc mobility is reduced.

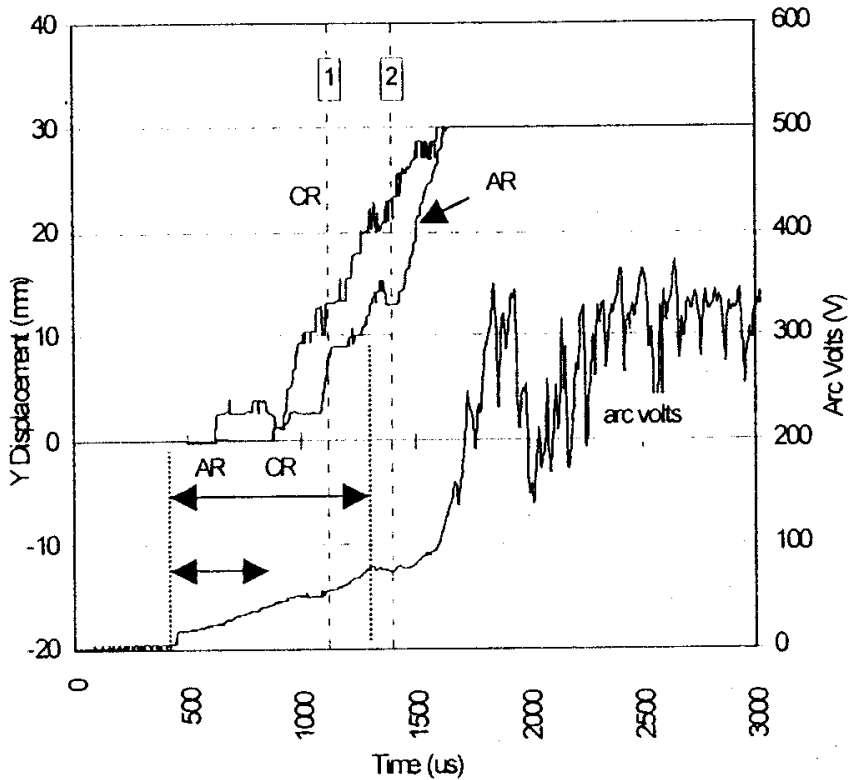

Fig. 2. Arc voltage with cathode root $(\mathrm{CR})$ and anode root (AR) motion.

\section{EXPERIMENTAL METHODS}

\section{A. Test System}

A high speed arc imaging system (AIS) has been used to record optical data of arc motion at sample rates of $1 \mathrm{MHz}$, [12]-[14]. The short circuit tests were carried out in a flexible test apparatus (FTA) designed to simulate the current limiting operation of a MCB [1], [19]. Fig. 1 shows details of the arc chamber used to simulate a typical MCB geometry. The fixed contact is connected to a long straight runner, and the circles over the arc chambers indicate the optical fiber positions. The contacts are opened with a solenoid mechanism, which operates independently of the fault current. The pivoting contact mechanism can be controlled to allow a range of opening velocities $1-10 \mathrm{~m} / \mathrm{s}$. The short circuit is simulated using a capacitive discharge system; circuit component values are defined in Table I. The opening of the contacts can be controlled and has been set in these experiments to $0.5 \pm 0.1 \mathrm{~ms}$ after the start of the short circuit current pulse.

Techniques have been developed that allow the trajectory of the two arc roots to be plotted separately from the AIS data, based on the method identified in [1], [19]. The method is used to measure the time period that each arc root remains in the contact region, known as the cathode root contact time and the anode root contact time.

\section{B. Method for Evaluating Arc Root Motion}

Optical methods of arc motion investigation have recently been improved with the advent of solid state high speed imaging using optical fiber arrays to monitor the arc motion [12]-[17]. Traditional methods using high-speed photography do not have sufficient time resolution for a detailed study of arc motion, as the event period of concern here is 1-3 ms, as shown in Fig. 2. Solid state imaging using CCD arrays are also not able to offer 


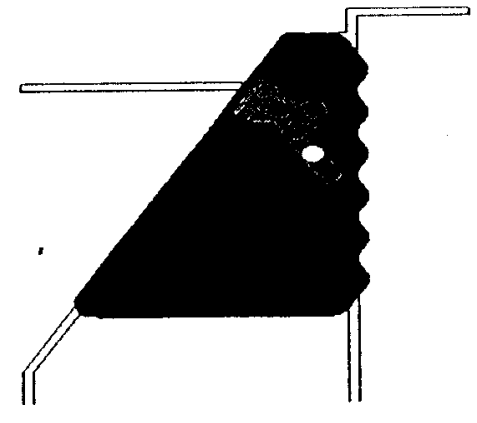

Fig. 3. Arc image at position 1 in Fig. 2.

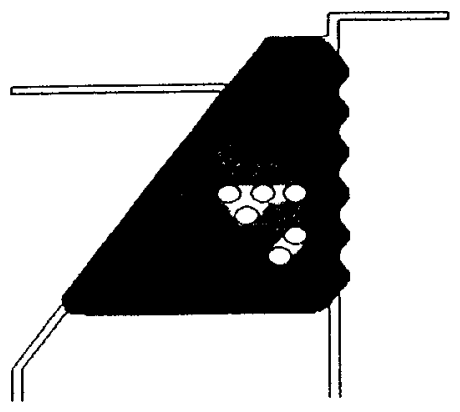

Fig. 4. Arc image at position 2 in Fig. 2.

the required time resolution, however an optical fiber array, connected to A-D circuitry can allow image resolution of 1 million pictures/s, allowing 1000 images per ms of the arc over the period of interest. The availability of comprehensive optical data permitted new direct measurements of arc contact time [2]. In a recent study [1], [19] parameters were defined to allow for a detailed study of the arc contact times for both anode and cathode roots on moving and fixed contacts. The use of the optical fiber array allows sections of the arc motion to be identified. In Fig. 2, both arc voltage and arc root trajectories are shown. The arc voltage is shown as the lower trace. The cathode root (CR) in this case on a fixed contact is shown to start moving away from the contact region at $0.9 \mathrm{~ms}$. The anode root (AR) on the moving contact starts to move at $0.6 \mathrm{~ms}$.

To allow a full analysis of parameters the moving contact time is defined as the time difference between the start of the arc and the point where the root passes $10 \mathrm{~mm}$ displacement. This corresponds to the root moving off the moving contact. This is defined as $t_{c m}(+)$, and is shown in the upper arrow in Fig. 2.

The fixed contact time is defined as period between the start of the arc and the start of the root motion away from the contact region. This is defined as $t_{c f}(-)$, and is shown in the lower arrow in Fig. 2. The $(+)$ and $(-)$ are used to define the polarity of the contact.

The arc images shown in Figs. 3 and 4 can be viewed with the root trajectories to show

1) arc root on the tip of the moving contact;

2) arc running in the arc chamber.

The time periods defined using these techniques allow a detailed analysis of the anode and cathode arc root motions. This allows a comparison with previous lower resolution methods and also allows a full study to obtain optimum performance.
TABLE II

CONTACt Materials, Used ON THE FIXEd Contact RunNer IN FIG. 1

\begin{tabular}{l|l}
\hline Material & Composition \\
\hline $\mathrm{CM}-3$ & $\begin{array}{l}\text { Silver cadmium tin indium } \\
\text { oxides (15\% metal oxides); }\end{array}$ \\
\hline $\mathrm{CM}-4$ & $\begin{array}{l}\text { Silver cadmium tin indium } \\
\text { oxides (18\% metal oxides) }\end{array}$ \\
\hline AgNi & \begin{tabular}{l} 
Silver Nickel (10\%); \\
\hline HGH
\end{tabular} \\
\hline M2-1 & $\begin{array}{l}\text { Silver Nickel }(0.15 \%) ; \\
\text { indium oxides); }\end{array}$ \\
\hline Ag\C & $\begin{array}{l}\text { Silver graphite contacts } \\
\text { (rectangular) }\end{array}$ \\
\hline M2 & $\begin{array}{l}\text { Silver tin indium oxide (15\% } \\
\text { metal oxides) }\end{array}$ \\
\hline
\end{tabular}

\section{Experimental Methods}

There are four experiments covered in this paper. In all cases the methodology used is well established and involves using new materials in the test chamber after 10 consecutive short circuit tests. The experiments are

1) influence of contact materials on the arc root motion. See Table II;

2) influence of venting on arc root motion for three conditions, opened, choked and closed vent;

3) influence of current. Three peak current levels, $50 \mathrm{~A}$, $1.4 \mathrm{kA}$, and $2 \mathrm{kA}$;

4) influence of velocity, low velocity $4 \mathrm{~m} / \mathrm{s}, 5.5 \mathrm{~m} / \mathrm{s}$ and high velocity $10 \mathrm{~m} / \mathrm{s}$.

The experimental constants are defined in Table I. The contact materials tested were all tested on the fixed contact runner except in the case of the $\mathrm{Ag} / \mathrm{C}$ contact materials whuch were also tested on the moving contact, in experiment 2 .

\section{RESULTS}

\section{A. Experiment 1}

In Fig. 5, the contact times are presented with the error band of $+/-1$ s.d. In all cases the contact materials are welded to the fixed contact, which is in all cases the cathode. The results show that for all contact materials the delay at the cathode, $t_{c f}(-)$ is between 300-400 $\mu$ s. The anode time on the moving contact $t_{c m}(+)$ is consistent between, 750-850 $\mu$ s.

\section{B. Experiment 2}

Fig. 6 shows the results of experiment 2, investigating the influence on the anode and cathode root motions. In tests (1-3) the $\mathrm{Ag} / \mathrm{C}$ contact material was welded to the moving contact. In this case the results showed a high degree of variability and are shown here for completeness. Tests (4-6) use the conventional arrangement with $\mathrm{Ag} / \mathrm{C}$ on the fixed contact. The results from Test 4 can be compared to the values in Fig. 5 for the $\mathrm{Ag} / \mathrm{C}$ 


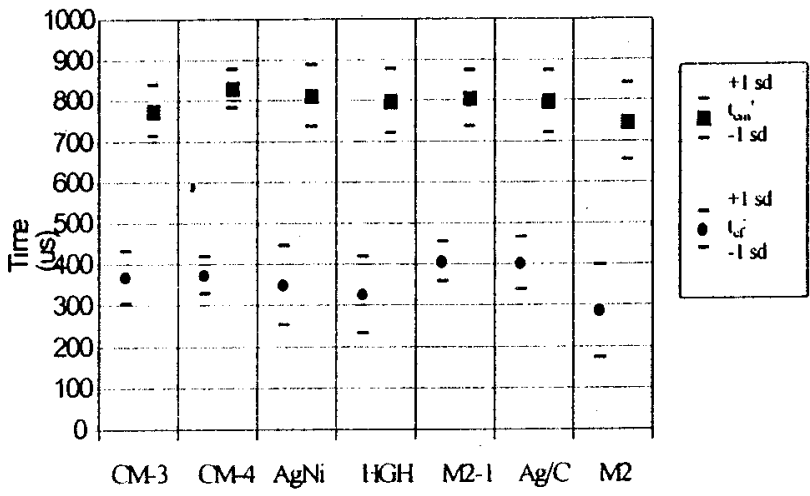

Fig. 5. Influence of contact materials, on contact times $(\mu \mathrm{s})$. The upper times are $t_{c m}(+)$ and the lower $t_{c f}(-)$. Peak current $2 \mathrm{kA}$, open vent, $10 \mathrm{~m} / \mathrm{s}$ contact speed.

material. The vent is shown to have an important influence on the anode contact time. As the vent is closed the pressure in the chamber increases leading to a delay in the anode root motion off the moving contact, increasing from 870 to $1050 \mu \mathrm{s}$. Reversal of the polarity, in tests 7-9, shows a similar influence on the cathode root motion (see Table III).

The motion on the fixed contact shows the higher degree of mobility of the anode root and there appears to be no significant connection with the vent condition.

\section{Experiment 3}

In experiment 3, consideration is given to the influence of current on the anode and cathode commutation from the moving contact. The results are shown in Fig. 7, for three levels of peak current.

The results in Fig. 7 confirm the expectation that increasing the current leads to a reduction in the delays both on the fixed contact runner and on the moving contact. The commutation delay from the anode moving contact to the fixed runner is lower than the cathode delay at $500 \mathrm{~A}$ (peak) but greater at $2 \mathrm{kA}$. The $2 \mathrm{kA}$ arc can be expected to generate a greater pressure increase in the chamber.

\section{Experiment 4}

Fig. 8 shows the influence of contact velocity on the anode and cathode root motion away from the moving contact.

\section{DISCUSSION}

The results of the influence of contact materials are shown in Fig. 5. For the conditions used the arc motion away from the fixed and moving contact, is not significantly affected by the contact material. The $\mathrm{Ag} / \mathrm{C}$ material used in the majority of circuit breaker applications does produce the longest delay on the fixed contact but the results show that the additional delay is insignificant.

Fig. 6 shows the effect of the venting arrangement on the arc root time on the moving and fixed contacts for both anode and cathode. The data show that the fixed contact $(\mathrm{Ag} / \mathrm{C}) \operatorname{arc}$ root times are unaffected by the arc polarity or venting under the conditions studied. However, the venting has a strong effect on

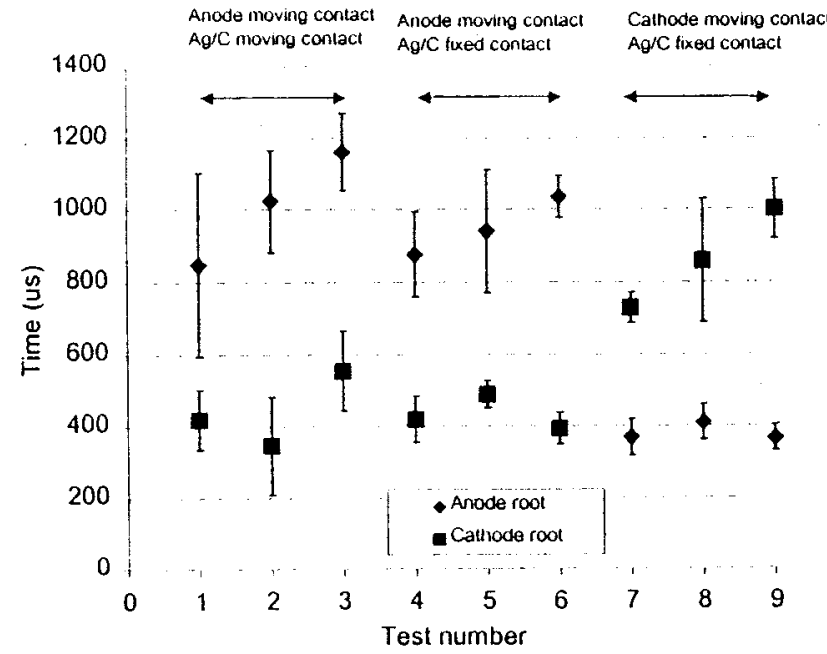

Fig. 6. Variation of venting conditions and polarity. To be viewed with Table III.

TABLE III

VARIABLES USED IN EXPERIMENT 2, CONSTANTS $v=10 \mathrm{~m} / \mathrm{s}$, $I($ peak $)=2 \mathrm{kA}$

\begin{tabular}{c|l|l|l}
\hline Test & Vent & Polarity & $\mathrm{Ag} / \mathrm{C}$ \\
\hline 1 & Open & Anode moving & Moving \\
\hline 2 & Choked & Anode moving & Moving \\
\hline 3 & Closed & Anode moving & Moving \\
\hline 4 & Open & Anode moving & Fixed \\
\hline 5 & Choked & Anode moving & Fixed \\
\hline 6 & Closed & Anode moving & Fixed \\
\hline 7 & Open & Cathode moving & Fixed \\
\hline 8 & Choked & Cathode moving & Fixed \\
\hline 9 & Closed & Cathode moving & Fixed \\
\hline
\end{tabular}

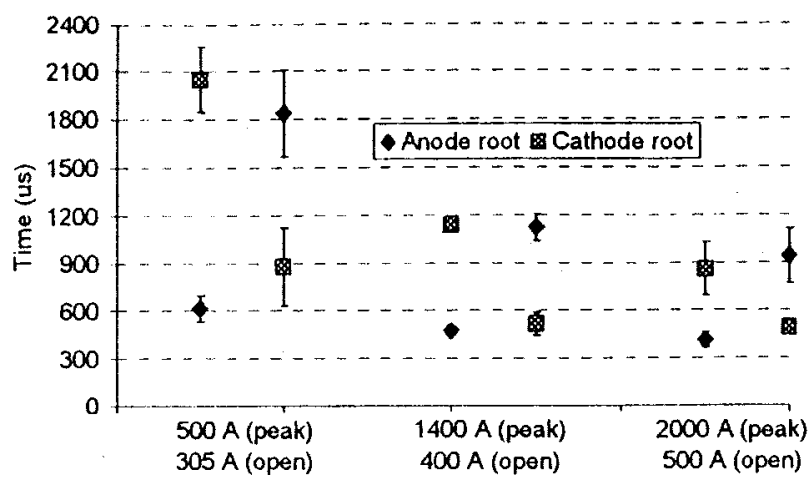

Fig. 7. Anode and cathode root motion on the moving contact as a function of peak supply current, and current at contact opening. For choked vent, $v=10$ $\mathrm{m} / \mathrm{s}, \mathrm{Ag} / \mathrm{C}$ on fixed contact.

the arc root time on the moving contact. This is demonstrated in Fig. 9.

As the vent area is increased the arc root times decrease. This reflects the expected improvement in arc mobility as the gas is permitted to flow out of the chamber through the vents at the rear of the arc chamber. However, the venting arrangement has a stronger influence on the cathode root motion than the anode. As the vent area is reduced toward zero the anode and cathode root times become similar at a value of around $1 \mathrm{~ms}$. 


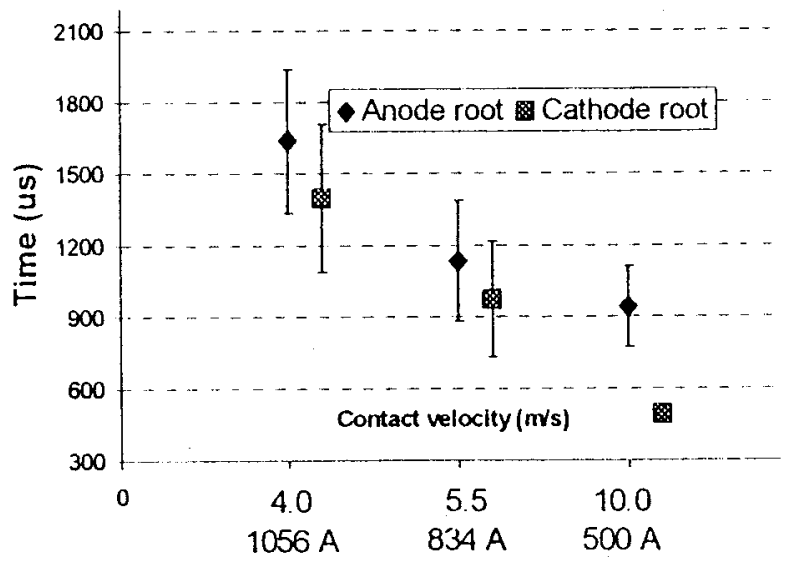

Fig. 8. Variation of contact velocity $(\mathrm{m} / \mathrm{s})$, with the associated current at contact opening.

The stronger effect of the venting on the cathode motion, and the lower cathode root times on the moving contact is contrary to expectations, where as discussed in Section II, the cathode delay time for crossing a gap has generally been observed to be longer than for an anode.

The reason for this difference is thought to lie in the gas flow conditions within the arc chamber, particularly around the moving contact. The arc produces a significant electrical power-for typical arcing conditions of $1000 \mathrm{~A}, 100 \mathrm{~V}$ the arc power is $100 \mathrm{~kW}$. This energy is deposited largely as heat in the contact materials and the arc gas. The emission of metallic vapor from the contact region and the heating of the gases in the arc chamber generate strong thermally driven flows. These flow away from the arc and out of the vents behind the arc stack, but also into the open region behind the contacts as shown in Fig. 10.

The data indicate that this flow pattern impedes transfer of the anode from the moving contact to a greater extent than the cathode. This may be due to a high gas flow rate behind the moving contact, which sweeps away the low mass of anodic gases and deionises the gap between the moving contact and the arc runner. This severely reduces energy transfer to the moving contact arc runner preventing the extension of the conductive arc column and the establishment of a new electron receptor site. Also, as discussed in Section II-A, the anode, once delayed, may be more impeded than the cathode.

The cathode is associated with a large volume of ionised material electrostatically drawn to the cathode region. The lower cathode mobility and higher cathode power dissipation also cause the generation of relatively high quantities of vaporized material. This will be entrained into the gas flow behind the moving contact to establish a conductive area behind the moving contact. Material will also be directed toward the arc runner by plasma jets, which are prevalent on the cathode. Both these effects combine to promote conditions favourable for establishing a new arc root on the moving contact.

When the flow through the arc stack is totally blocked, then both types of arc root are delayed in their transfer from the moving contact to a similar extent. In this case transfer may be effectively prevented by the blocked venting and only occurs

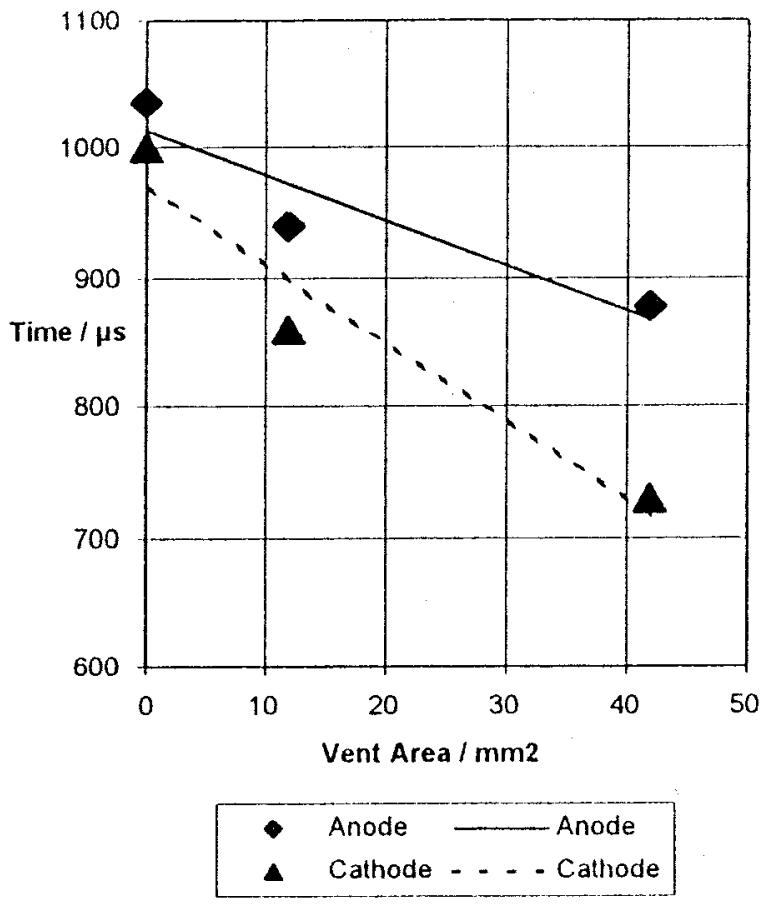

Fig. 9. Effect of vent area on moving contact arc root times.

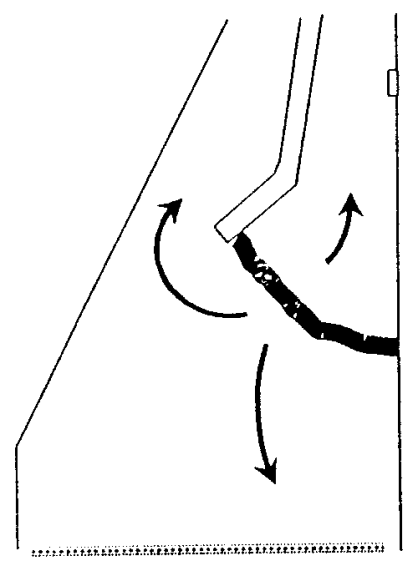

Fig. 10. Schematic diagram of gas flow from the arc area during movement along the moving contact. Arrows indicate gas flow directions.

when there is only a small gap, or direct electrical contact between the moving contact and the arc runner.

The foregoing discussion shows how the contact movement and its effect on the gas flow in the arc chamber, has a critical influence on the arc root mobility. This is studied in more detail in Fig. 8 where the moving contact arc root times are plotted against the moving contact velocity in the range $4-10 \mathrm{~m} / \mathrm{s}$ (choked venting arrangement). As the contact velocity is increased, the arc root time decreases. This accords with the results of Belbel and Lauraire [18], but shows a continuous improvement in arc mobility with contact speed as far as the moving contact is concerned. It should be noted that, as the contact velocity is increased the contacts also open earlier in the current waveform resulting in a progressive reduction in arc current on opening as well as peak current. This will reduce 
the electromagnetic force on the arc and at the arc roots which would be expected to favor increased arc contact times. The effect of contact velocity alone would therefore be expected to be even greater than that indicated by Fig. 8 .

\section{CONCLUSION}

The contact materials investigated have a minimal influence on the arc root motion away from the contact region.

The vent of the arc chamber is critical to the arc root motion away from the contact region. It has a major influence on the anode and cathode root motion and commutation from the moving contact on to an arc runner. The gas flow in the region of the moving contact is proposed as the mechanism resulting in the delay of the anode arc root. The physical processes occurring in the arc roots have been used to explain this observation.

\section{ACKNOWLEDGMENT}

The authors would like to thank Dr. P. Jeffery for the experimental contribution.

\section{REFERENCES}

[1] J. W. McBride and P. A. Jeffery, "Anode and cathode arc root movement during contact opening at high current," IEEE Trans. Comp., Packag., Manufact. Technol. A, vol. 22, pp. 38-46, Mar. 1999.

[2] J. W. McBride, P. M. Weaver, and P. Jeffery, "Arc root mobility during contact opening at high current," IEEE Trans. Comp., Packag., Мanufact. Technol. A, vol. 21, pp. 61-67, Mar. 1998.

[3] P. A. Jeffery, J. W. McBride, J. Swingler, and P. M. Weaver, "An investigation into arc contact phenomena and current limiting performance of miniature circuit breakers using the Taguchi design of experiments," in Proc. 19th Int. Conf. Elect. Contacts, Sept. 14-17, 1998.

[4] W. Rieder, "Interaction between magnet-blast arcs and contacts," in Proc. 28th IEEE Holm Conf. Electrical Contacts, Sept. 13-15, 1982, pp. 3-10.

[5] E. Gauster and W. Rieder, "Arc lengthening between divergent runners: Influence of arc current, geometry, and materials of runners and walls," in Proc. 42nd IEEE Holm Conf. Elect. Contacts, Chicago, IL, Sept. 1996, pp. $1-10$.

[6] J. W. McBride and P. M. Weaver, "A review of arcing phenomena in low voltage current limiting circuit breakers," in Proc. IEE SMT, London, U.K., 2000.

[7] A. E. Guile, "Arc electrode phenomena," Proc. Inst. Elect. Eng., vol. 118, no. 9R, pp. 1132-1155, Sept. 1971.

[8] A. E. Guile, T. J. Lewis, and P. E. Secker, "The motion of cold-cathode arcs in magnetic fields," Proc. Inst. Elect. Eng., vol. 108, pp. 462-470, 1961.

[9] J. G. J. Sloot and G. M. V. v. d. Bosch, "Some conditions for arc movement under the influence of a transverse magnetic field," Holectechniek, vol. 2, no. 3, pp. 98-106, 1972.

[10] K. Poeffel, "Influence of the copper electrode surface on initial arc movement," IEEE Trans. Plasma Sci., vol. PS-8, pp. 443-448, Dec. 1980.

[11] W. Widmann, "Arc commutation across a step or a gap in one of two parallel copper electrodes," IEEE Trans. Comp., Hybrids, Manufact. Technol., vol. CHMT-8, pp. 21-28, Mar. 1985.

[12] P. M. Weaver and J. W. McBride, "High speed, medium resolution arc imaging in current limiting devices," in Proc. 17th Int. Conf. Elect. Contacts, July 1994.

[13] _ "Arc motion in current limiting circuit breakers," in Proc. 16th Int. Conf. Elect. Contacts, U. K., Sept. 1992, pp. 285-288.

[14] - "Magnetic and gas dynamic effects on arc motion in miniature circuit breakers," IEEE Trans Comp., Packag., Manufact. Technol. A, vol. 17, pp. 39-45, Mar. 1994.
[15] J. J. Shea, D. Boles, Y. K. Chien, and R. Zeigler, "Computer animated digital arc diagnostic system," in Proc. IEEE Holm Conf. Elect. Contacts, Pittsburgh, PA, Sept. 1993, pp. 237-243.

[16] J. W. McBride, P. M. Weaver, and P. Jeffery, "Arc root mobility during contact opening at high current," in Proc. IEEE Holm Conf. Elect. Contacts, Chicago, IL, Sept. 1996, pp. 27-34.

[17] J. W. McBride and P. A. Jeffery, "The design optimization of current limiting circuit breakers," in Proc. IC-ECAAA Conf., Xian, China, May 1997, pp. 354-360.

[18] E. M. Belbel and M. Lauraire, "Behavior of switching arc in low voltage current limiter circuit breaker," IEEE Trans. Comp., Hybrids, Manufact. Technol., vol. CHMT-8, pp. 3-12, Mar. 1985.

[19] J. W. McBride and P. A. Jeffery, "Anode and cathode arc root movement during contact opening at high current," IEEE Trans. Comp., Packag., Manufact. Technol. A, vol. 22, p. 344, June 1999.

John W. McBride received the M.S. degree in aeronautical engineering from the University of Southampton, Southampton, U.K., in 1978 and the Ph.D. degree in electrical contact phenomena from Plymouth University, Plymouth, U.K., in 1986.

From 1985 to 1987, he lectured in the Mechanical Engineering Department, Plymouth University, and since 1987, has been a Lecturer, Senior Lecturer, and (since 1999) a Reader in instrumentation and measurement in the School of Engineering Science and the Electrical Engineering Department, University of Southampton. He is Chair of the Electro-Mechanical Research Group. His main research interests include electrical contacts, metrology, and instrumentation.

Dr. McBride is a member of the IEE, a Chartered Engineer, and Vice Chair of IEE professional group S3 Electron Physics, Plasmas, and Applications. He is Associate Editor of the IEEE TRANSACTIONS ON COMPONENTS AND PACKAGING TECHNOLOGIES and a member of the Organizing Committee, IEEE Holm Conference on Electrical Contacts.

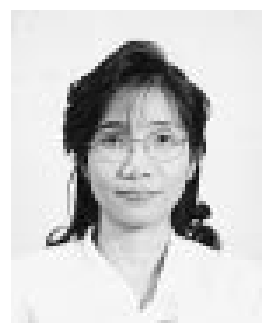

Kesorn Pechrach (M'92) received the B.Eng. degree in electrical engineering from the Khonkaen University, Thailand, in 1992, the M.Eng. degree in energy technology from the King Mongkut's University of Technology, Thonburi, Thailand, in 1997, and is currently pursuing the Ph.D. degree at the Electro-Mechanical Research Group, University of Southampton, U.K.

She has worked for consulting engineer companies as a Lead Electrical Engineer for nearly ten years. Her responsibilities included the design and construction engineer supervision of electrical facilities for industrial plants, commercial building, roadways, refineries, and HV substations.

Ms. Pechrach is a member of AMIEE and a Chartered Electrical Engineer of the Engineering Institute of Thailand.

Paul M. Weaver received the B.A. degree in natural science (with honors) from the University of Cambridge, Cambridge, U.K. and the Ph.D. degree in aeronautical engineering from the University of Southampton, U.K.

He is Research Manager at PBT, Ltd, Harlow, U.K., a manufacturer and developer of piezo actuators and circuit protection devices. He has been working in the industry since 1993 in research and development of circuit breakers and related switching systems and has published widely in this field. Prior to this, he was a Research Fellow at Southampton University researching short circuit arc phenomena. His research interests include switching arc phenomena, instrumentation, smart materials actuation, and sensor technologies.

Dr. Weaver is a member of the IEE. 